\title{
The Fit Family Challenge: A Primary Care Childhood Obesity Pilot Intervention
}

\author{
Bonnie T. Jortberg, PhD, RD, CDE, Raquel Rosen, MA, Sarah Roth, MA, \\ Luke Casias, MD, L. Miriam Dickinson, PhD, Letoynia Coombs, EdD, \\ Nida S. Awadallah, MD, Meaghann K. Bernardy, MD, and W. Perry Dickinson, MD
}

Background: Childhood obesity has increased dramatically over several decades, and the American Academy of Pediatrics has recommended primary care practices as ideal sites for the identification, education, and implementation of therapeutic interventions. The objective of this study was to describe the implementation and results for the Fit Family Challenge (FFC), a primary care-based childhood obesity intervention.

Methods: A single-intervention pilot project that trains primary care practices on childhood obesity guidelines and implementation of a family-focused behavior modification curriculum. A total of 29 family medicine and pediatric community practices in Colorado participated. Participants included 290 patients, aged 6 to 12 years, with a body mass index (BMI) above the 85th percentile. The main outcome measure included the feasibility of implementation of a childhood obesity program in primary care; secondary outcomes were changes in BMI percentile, BMI $z$-scores, blood pressure, and changes in lifestyle factors related to childhood obesity.

Results: Implementation of FFC is feasible; statically significant changes were seen for decreases in BMI percentile and BMI $z$-scores for participants who completed 9 to 15 months of follow-up; lifestyle factors related to childhood obesity in proved Spanish-speaking families and food insecurity were associated with less follow-up time $(P<.01)$.

Conclusions: A primary care-based childhood obesity intervention may result in significant clinical and lifestyle changes. (J Am Board Fam Med 2016;29:434-443.)

Keywords: Behavior Therapy, Blood Pressure, Body Mass Index, Child, Colorado, Curriculum, Family Practice, Follow-Up Studies, Food Supply, Life Style, Outcome Assessment (Health Care), Pediatric Obesity, Pediatrics, Pilot Projects, Primary Health Care, United States

Childhood obesity has become a major area of health concern with increasing prevalence over the past several decades. According to the Centers for Disease Control and Prevention (CDC), obesity rates in the United States have doubled among

This article was externally peer reviewed.

Submitted 28 July 2015; revised 19 February 2016; accepted 26 February 2016.

From the Department of Family Medicine, University of Colorado School of Medicine, Aurora (BTJ, LMD, LC, NSA, MKB, WPD); the Colorado Academy of Family Physicians (RR, SR, LC); and Rose Family Medicine Residency Program, Rose Medical Center, Denver, CO (NSA, MKB).

Funding: The Colorado Health Foundation.

Conflict of interest: none declared.

Corresponding author: Bonnie T. Jortberg, $\mathrm{PhD}, \mathrm{RD}$, CDE, Department of Family Medicine, University of Colorado School of Medicine, 12631 E. 17th Ave, Aurora, CO 80045 (E-mail: bonnie.jortberg@ucdenver.edu). children and quadrupled among adolescents in the past 30 years. ${ }^{1-3}$ In the United States, more than one third of children and adolescents between the ages of 6 to 19 years were considered overweight or obese in 2011 to $2012 .{ }^{1,2}$ The percentage of obese children between the ages of 6 to 11 years increased from $7 \%$ in 1980 to nearly $18 \%$ in 2011 to 2012 . For adolescents between the ages of 12 to 19 years, obesity increased from $5 \%$ to just over $20 \%$ in the same time period. ${ }^{1-3}$

Childhood obesity can have detrimental immediate and long-term health effects. Obese children can suffer from sleep apnea and joint problems, as well as social and psychological problems, including poor self-esteem. ${ }^{3-6}$ Obese children are also more likely to have risk factors for cardiovascular disease, including hypertension, hyperlipidemia, 
and impaired glucose tolerance, increasing their risk of developing diabetes. ${ }^{3,7-9}$ These health problems can be carried into adulthood, causing heart disease, stroke, and diabetes, as well as an increased risk of many types of cancers, including cancer of the breast, colon, prostate, and pancreas. ${ }^{3,5,10}$

In 2009 the CDC initiated the Common Community Measures for Obesity Prevention Project (the Measures Project), which identified and recommended a set of strategies aimed at preventing obesity. ${ }^{11}$ These strategies included promoting physical activity and healthy food and beverage choices, and limiting sedentary activity, particularly among children and adolescents. Since many of the recommendations focused on community and local government intervention, several limitations were acknowledged. ${ }^{11}$ The latest Institute of Medicine recommendations include strategies geared at preventing obesity and incorporate screening, diagnosis, and treatment of obesity; they also expand the role of health care providers to include improving population health in their patients' communities. ${ }^{12}$ In 2005, representatives from 15 national health care organizations, brought together by the American Medical Association in collaboration with the CDC and the Health Resources and Services Administration, formed an expert committee. In 2007 the expert committee published revised recommendations on childhood obesity to include annually reviewing body mass index (BMI) to screen for obesity, limiting intake of sugar-sweetened beverages, encouraging consumption of recommended quantities of healthy fruits and vegetables, limiting screen time to $<2$ hours/day, and increasing physical activity. They recommended a multidisciplinary approach within the primary care office as well as family involvement. ${ }^{13}$ The US Preventive Services Task Force (USPSTF) recommends screening children $\geq 6$ years old for obesity and offering comprehensive behavioral interventions and intensive counseling to promote weight loss (grade B). ${ }^{14}$ Identifying trajectories of childhood weight gain may be beneficial for primary care clinicians and suggests that, under usual care, BMI $z$-scores tend to remain stable or even increase over time. A recently published study describing childhood weight gain using BMI $z$-score trajectories in a low-income childhood population found that $\mathrm{BMI} z$-scores increased with increasing age in all groups and were highest among Hispanic boys and black girls. ${ }^{15}$
Multiple published studies have shown significant improvements in BMI and/or weight loss in the pediatric population when lifestyle interventions included increasing physical activity and improving the diet. ${ }^{16-22}$ Family involvement and longer-term interventions generally showed better results. ${ }^{23-27}$ The primary care practice may be an ideal site in which to identify overweight and obese children, educate parents and children about the health risks of obesity, and establish and implement therapeutic interventions. The 2003 policy statement issued by the American Academy of Pediatrics $^{28}$ recommends that prevention and treatment of obesity in children and adolescents be provided within the primary care practice, where children are seen frequently for both health maintenance and sick care visits. Unfortunately, several barriers in the current primary care environment inhibit the implementation of these recommendations.

Several recent surveys of provider attitudes and practices related to childhood obesity revealed that many providers have not had training in behavioral interventions, including motivational interviewing and the treatment of overweight children, and therefore do not feel confident in counseling or managing their overweight and obese patients. ${ }^{29}$ Historically, there are few studies examining the implementation of a childhood obesity program in primary care; however, 4 recently published studies looked at this issue. One study from Israel showed an improvement in mean $z$-scores with a primary care multidisciplinary team approach to weight loss. ${ }^{30}$ The use of a brief, structured intervention with flashcards and take-home games with residency-based physicians improved their self-efficacy regarding office-based childhood obesity discussions, although patient outcomes were not reported. ${ }^{31}$ The Maine Youth Overweight Collaborative ${ }^{32}$ implemented behavioral strategies that focused on implementation of the 5-2-1-0 messages ( $\geq 5$ servings of fruits and vegetables; $\leq 2$ hours of screen time; $\geq 1$ hour of daily physical activity; and 0 servings of sugar-sweetened beverages) and saw parents' perceived improvement in providers' behavior and rates of counseling for their child regarding obesity. A study published by Duggins et $\mathrm{al}^{33}$ found that children randomized in a primary care office to either nutrition classes alone or nutrition classes plus a YMCA membership improved their nutrition intake, but the YMCA membership group did not induce more weight loss. 
Figure 1. Fit Family Challenge (FFC) flow diagram. BMI, body mass index; BP, blood pressure; CM, care manager; HSK, HeartSmartKids.

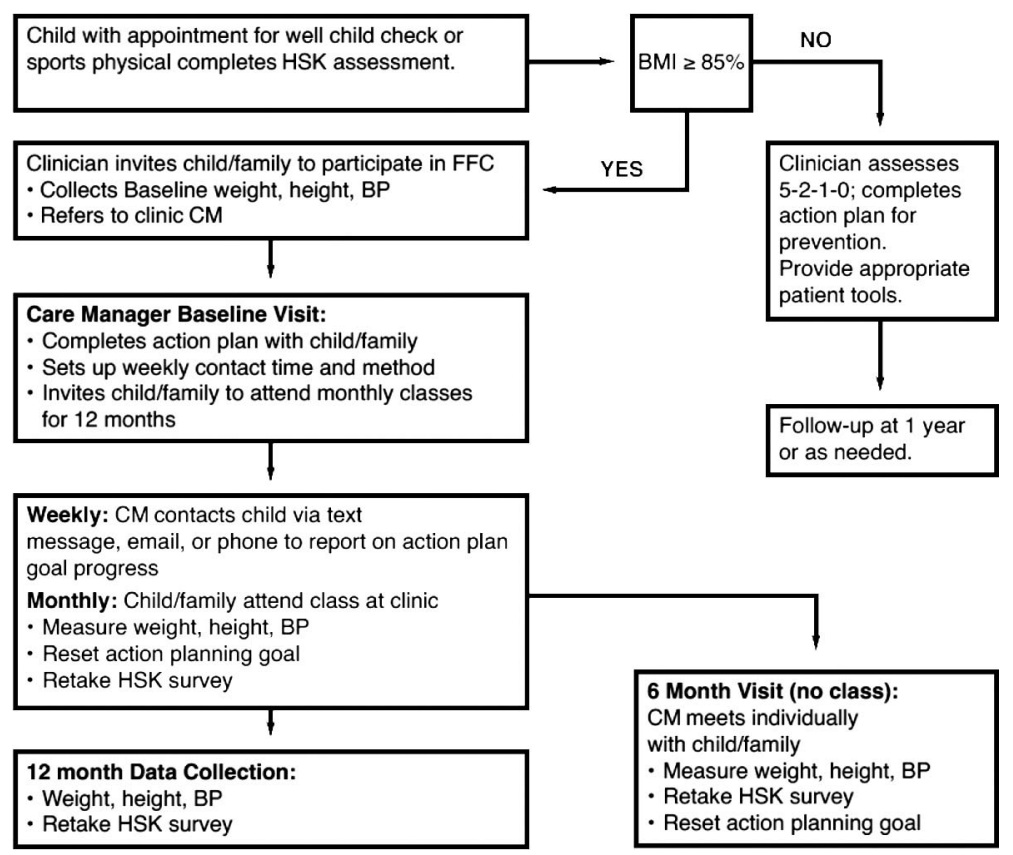

\section{Objective}

The primary aim of this pilot study was to test whether a childhood obesity intervention delivered by trained primary care clinicians and staff could be implemented, followed by changes in BMI, blood pressure, and at-risk lifestyle factors.

\section{Methods}

\section{Participants}

This pilot study was conducted at 29 primary care practices throughout Colorado. Practices were recruited through an article in the Colorado Academy of Family Physicians (CAFP) quarterly magazine and emails to members of CAFP and the Colorado chapter of the American Academy of Pediatrics. Practices participated from September 2011 to May 2014. Eighteen practices were in an urban location, 11 were in a rural location, and 6 were federally qualified health centers.

Each practice was asked to recruit a minimum of 10 children and their families using a web-based questionnaire called HeartSmartKids. To determine eligibility for the Fit Family Challenge (FFC), the practices were asked to screen all children between the ages of 6 and 12 years scheduled for an appointment for a yearly or sports physical or during other visits at the discretion of the clinician. Children with a BMI percentile $\geq 85$ were invited to participate in the FFC through a printed invitation and discussion with their clinician. Exclusion criteria included children with psychiatric diseases requiring medication that causes obesity, depression, or schizophrenia; epilepsy requiring medications that cause obesity; genetic syndromes that affect body weight (eg, Prader-Willi syndrome); or endocrine disorders (eg, Cushing disease, hypothyroidism, growth hormone deficiency, pseudoparathyroidism type 1a, familial hyperlipidemia, hypothalamic obesity-brain trauma, cranial growth abnormalities, and medication-induced obesity from treatment of other illnesses such as steroids for asthma or insulin for type 1 diabetes). Practices implemented a "rolling recruitment" strategy whereby they could continually enroll participants through the duration of the project. Figure 1 describes the screening process and the intervention flow.

\section{Protections}

This pilot project was reviewed by the Colorado Multiple Institutional Review Board and approved as exempt from human subjects research review because only de-identified patient data were obtained from FFC practices. 


\section{FFC Intervention}

Participation in the FFC involved (1) weekly contact and goal-setting with the child's primary care practice's designated FFC care manager, (2) attendance at a monthly group visit with parent(s) and other family members, and (3) collection of weekly goals and monthly weight, height, blood pressure, and lifestyle factors. Participants completed a questionnaire on an iPad provided to each practice at baseline and at each monthly group visit. The questionnaire, called HeartSmartKids, asked questions to determine lifestyle factors related to 5-2-1-0. At the initial visit, the FFC care manager set up a weekly preferred contact method with the child or parent (email, phone call, or text messaging).

A step-by-step facilitator's guide and monthly group visit curriculum was developed and distributed to the practices by the project team, including a family physician, a project coordinator, a researcher in the Department of Family Medicine at the University of Colorado School of Medicine, and the CAFP chief executive officer. The curriculum for the FFC was based on the 5-2-1-0 message. Leaders from participating practices attended a 1-day training session that included an overview of the FFC, training on the monthly group visit curriculum, data collection recommendations, implementation of the HeartSmartKids questionnaire, and motivational interviewing techniques. Members of the project team also conducted a 2-hour rapid improvement activity at each practice so that all practice providers and staff were trained with HeartSmartKids and the FFC curriculum. Each practice leader participated in monthly conference calls for project updates and to share successes and challenges. Practices also participated in biannual learning collaboratives. Last participating practices had access to the project team for technical support regarding program implementation and data collection.

Monthly group visits were facilitated by each practice's lead clinician and designated care manager, typically a medical assistant, nurse, dietitian, social worker, or behavioral health specialist. At the monthly group visits, each child had body weight, height, and blood pressure taken by a trained staff member and completed the HeartSmartKids questionnaire. These data were entered into the HeartSmartKids database using a de-identified participant number. At each group visit, the child and parent(s) participated in the group activity and completed an action plan to take home with a goal to work on over the next 4 weeks. Each child and parent set up a time and method for weekly follow-up with practice staff to discuss progress toward meeting the monthly goal. Some practices were able to bill for the group visit. More information about the FFC curriculum can be found on the FFC website at www.ourfitfamily.org.

\section{Exit Interviews}

Qualitative interviews using a semistructured interview guide were conducted at the time practices completed the program. Interviews included the lead clinician and key staff involved in the FFC.

\section{Statistical Methods}

Descriptive statistics were generated for patient sociodemographic characteristics. Primary outcomes were BMI percentile and BMI $z$-scores over time. Secondary outcomes included systolic and diastolic blood pressures, fruit and vegetable intake, physical activity, family activity, hours per day of screen time, sugar-sweetened beverage intake, and eating out over time. Likelihood-based approaches (ie, general linear mixed effects modeling) were used to analyze clinical and lifestyle outcomes (SAS Proc Mixed), adjusting for clustering of patients within practices and repeated measures on patients over time (random intercepts and slopes for patients, random intercepts for practice if significant). Analyses were adjusted for patient age, sex, primary language, and height and weight (BP only). All available data were used in the analyses during the time period when the child participated in FFC. The data were examined for possible nonignorable missingness (MNAR) and pattern mixture model approaches, ${ }^{34}$ grouping participants according to duration of follow-up, and were added to the primary models described above to determine whether trajectories differed by time in the study. Sensitivity analyses using regression-based multiple imputation $^{35}$ were used for BMI percentile and BMI zscores. Analyses were performed using SAS version 9.4 (SAS Institute, Inc., Cary, NC).

\section{Results}

Between September 2011 and April 2014, 290 children plus family members participated in the FFC, and 264 children met the criteria to be included in the analysis. The mean age of the children 
Table 1. Fit Family Challenge Participant

\section{Characteristics}

\begin{tabular}{lc}
\hline Indicator & Participants, $\mathrm{n}(\%)$ \\
\hline Female & $146(50)$ \\
Male & $144(50)$ \\
English as first language & $208(71)$ \\
Spanish as first language & $82(28)$ \\
\hline
\end{tabular}

participating in FFC was 9 years (standard deviation $[\mathrm{SD}] \pm 2.0$ ). Table 1 describes the participants' baseline characteristics.

Outcomes measures of BMI percentile, BMI zscore, systolic and diastolic blood pressures, and lifestyle factors related to 5-2-1-0 through completion of the HeartSmartKids questionnaire were recorded at baseline and then monthly at the group visit. Several children were found to have a baseline BMI below the 85 th percentile and were removed from the outcomes analysis, leaving 264 in the final cohort for clinical outcomes. Because of the rolling enrollment, children had variable durations of follow-up time: $70 \%$ of children had a maximum follow-up time of 9 to 15 months, $17 \%$ had a maximum follow-up time of 6 to 9 months, $7 \%$ had a maximum follow-up time of 3 to 6 months, and $6 \%$ had a maximum follow-up time $<3$ months. Of participants, $39 \%$ completed at least 3 to 6 months of the interventions, $23 \%$ completed at least 6 to 9 months, and $17 \%$ completed 9 to 15 months. Importantly, children from Spanish-speaking families and children from families that reported at least some food insecurity (versus a never or no response) had less follow-up time $(P<.01)$. Age, sex, baseline BMI $z$-scores, readiness to work on family eating and activity, confidence in ability to make changes in family eating and activity, and concern about their child's health were not associated with duration of follow-up (all $P>.10$ ).

\section{Clinical Outcomes}

Because of high dropout rates and the inherent difficulty in detecting nonignorable missingness, pattern mixture approaches were used to analyze outcomes, with participants grouped by duration of time in the study. Overall, baseline BMI percentile was 97.1 ( $\mathrm{SD} \pm 3.0$ ); BMI $z$-score, 2.0 (SD \pm 0.47 ); systolic blood pressure, $106.0 \mathrm{mmHg}$ ( $\mathrm{SD} \pm 9.6$ ); and diastolic blood pressure, $67.7 \mathrm{mmHg}(\mathrm{SD} \pm 8.1$ ). Figure 2 and Table 2 show change in BMI percen- tile for participants, grouped by time in study. In the primary analysis, BMI percentile decreased significantly for participants who completed at least 6 to 9 months of follow-up but did not decline significantly for participants who completed only 3 to 6 months. BMI $z$-scores decreased significantly for participants who completed 9 to 15 months but not for participants who completed less time in the study. Sensitivity analyses using regression-based multiple imputation for missing data showed significant declines for participants who completed 9 to 15 months of follow-up but not for participants with less time in the study (Tables 2 and 3). Systolic and diastolic blood pressure did not change significantly from baseline.

\section{Lifestyle Factors}

Change trajectories for lifestyle outcomes from the HeartSmartKids questionnaire did not differ by duration in the study, so overall estimates are presented in Table 4 as change per 3 months. Estimated overall change will obviously be greater for children who participate over a longer period of time; data are insufficient to determine whether improvements continue at the same rate for participants with less follow-up time. Among participants who completed any follow-up visits there were statistically significant improvements in daily fruit and vegetable intake $(P<.0001)$; days with $\geq 60$ minutes of physical activity $(P<.0001)$, the number of times per week of family activity $(P<.0001)$; daily screen time $(P<.05)$; intake of sugar-sweetened beverages $(P<.0003)$; and number of times eating out per week $(P<.001)$.

\section{Exit Interviews}

Fifteen exit interviews were conducted with the FFC practices. Interviews were transcribed and an iterative process was used to identify and refine themes around facilitators for FFC implementation and barriers and challenges for FFC sustainability.

Qualitative themes for facilitators for implementation and sustainability included (1) a "shelfready" program and curriculum that practices could implement easily; (2) ease of use of a screening tool that helped clinicians identify overweight/ obese children and children at risk of obesity; and (3) ease of use of the group visit curriculum and emphasis on group participation. Barriers identified for lack of sustainability included (1) a lack of re- 
Figure 2. Body mass index (BMI) percentile (top) and $z$-score (bottom), by duration in the program.

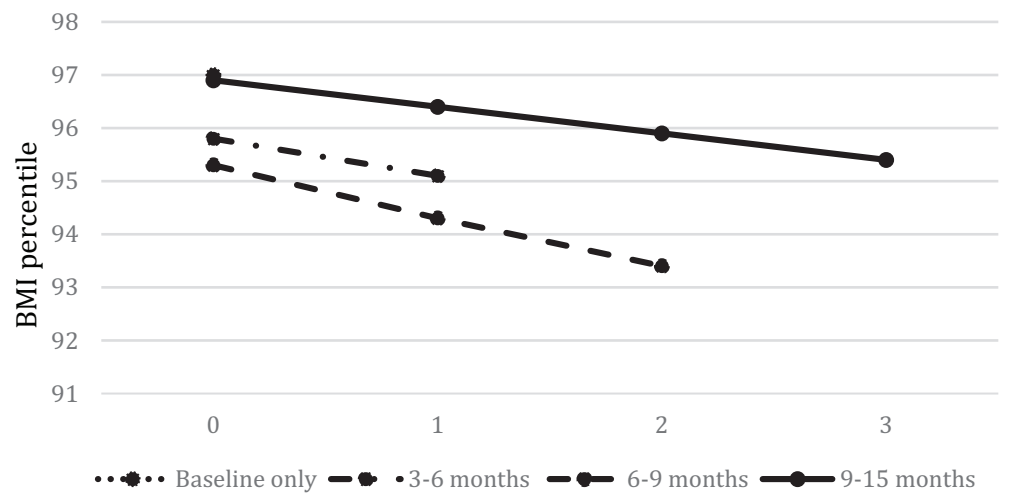

Duration

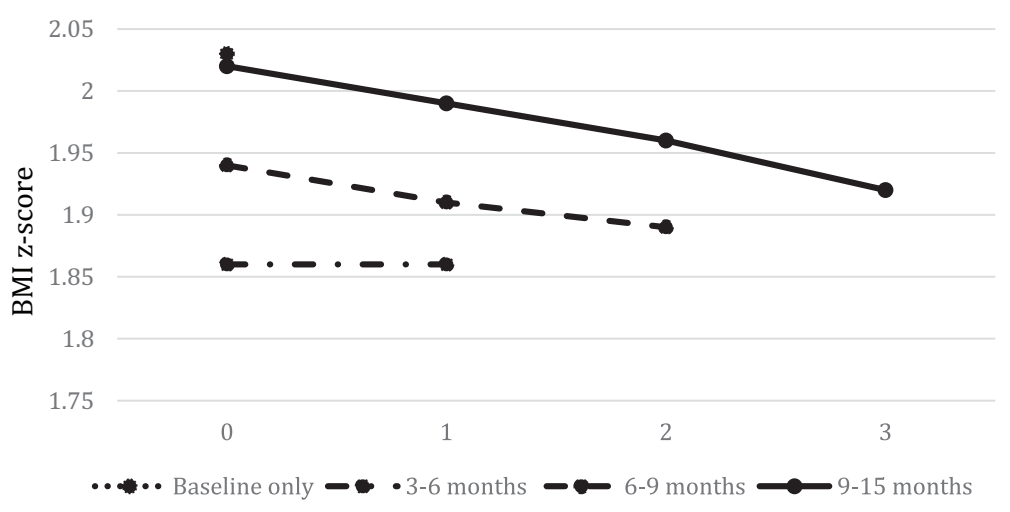

Duration

imbursement for screening for pediatric obesity or implementation of the FFC; (2) a lack of qualified staff to deliver the FFC intervention; and (3) challenging and time-consuming participant recruitment in many of the practices.

\section{Discussion}

There were significant improvements in BMI percentile among participants who stayed in the program at least 6 months and improvement in BMI $z$-scores among participants who stayed in at least 9 months; lifestyle outcomes also significantly improved. However, it is uncertain whether this improvement in BMI percentile and BMI $z$-scores can

Table 2. Clinical Outcomes

\begin{tabular}{lccr}
\hline Outcome & $\begin{array}{c}\text { Baseline } \\
\text { Visits } \\
(\mathrm{n}=264)\end{array}$ & $\begin{array}{c}\text { Change per } \\
\text { 3 Months }\end{array}$ & $\begin{array}{r}\text { Overall } \\
P \text { Value }\end{array}$ \\
\hline BMI percentile & 2.92 & +0.35 & $<.0001$ \\
BMI z-score & 1.62 & -0.03 & .1925 \\
\hline
\end{tabular}

BMI, body mass index. be attributed to the intervention because of the high dropout rate. Of primary significance is the finding those children from Spanish-speaking families and children from families that reported at least some food insecurity had less follow-up time in the program. Our findings corroborate with those of 2 other studies that found food insecurity increased the odds of childhood obesity in young Hispanic children ${ }^{36}$ and another study that found the risk of dropping out of a multidisciplinary obesity treatment program increased by $20 \%$ for each unit increase in the adolescent's social insecurity score. ${ }^{37}$ High attrition rates are seen in both adult and pediatric weight management programs, ${ }^{38,39}$ and our completion rates align with those in the literature.

The results from our pilot program and these 2 studies show the need to develop culturally appropriate childhood obesity interventions and strategies to engage these families, and the importance of addressing the issue of food and social insecurity.

Of interest was that significant changes in BMI percentile did not occur until at least 9 months of 
Table 3. BMI Percentile and BMI $z$-Score Changes

\begin{tabular}{|c|c|c|c|c|c|}
\hline \multirow[b]{2}{*}{ Outcome } & \multirow[b]{2}{*}{ Last Follow-up Time } & \multicolumn{2}{|c|}{ Original Sample } & \multicolumn{2}{|c|}{ multiple imputation } \\
\hline & & $\begin{array}{l}\text { Change per } 3 \text { Months, } \\
\text { Coefficient (SE) }\end{array}$ & $P$ Value & $\begin{array}{l}\text { Change per } 3 \text { Months, } \\
\text { Coefficient (SE) }\end{array}$ & $P$ Value \\
\hline \multirow[t]{4}{*}{$\mathrm{BMI}$ percentile } & Baseline & - & - & - & - \\
\hline & 3-6 Months & $-0.64(0.50)$ & .2023 & $-0.33(0.29)$ & .2722 \\
\hline & 6-9 Months & $-0.92(0.37)$ & .0137 & $-0.30(0.37)$ & .4202 \\
\hline & 9-15 Months & $-0.49(0.24)$ & .0391 & $-0.45(0.17)$ & .0094 \\
\hline \multirow[t]{4}{*}{$\mathrm{BMI} z$-score } & Baseline & - & - & - & - \\
\hline & 3-6 Months & $-0.006(0.030)$ & .8546 & $-0.007(0.040)$ & .8652 \\
\hline & 6-9 Months & $-0.024(0.021)$ & .2413 & $-0.036(0.052)$ & .5097 \\
\hline & 9-15 Months & $-0.030(0.013)$ & .0217 & $-0.048(0.023)$ & .0329 \\
\hline
\end{tabular}

BMI, body mass index; SE, standard error.

participation. This may have been a result of the low intensity of the program, high variability in BMI percentile trajectories among children, or insufficient follow-up time to establish stable weight trajectories. The USPSTF recommends a moderate- to high-intensity program that involves $>25$ hours of contact with the child and/or family over a 6 -month period. ${ }^{14}$ However, this level of contact and activity is often neither practical nor sustainable for families or practices. To accommodate the needs of busy primary care practices in the current fee-for-service environment and the lack of reimbursement for childhood obesity care, the FFC involved approximately 2 hours of contact per month, or about half of the intensity recommended by the USPSTF. This could have delayed the effect but also could produce more sustainable results.

The results of this pilot project indicate that a childhood obesity treatment program can be implemented in the primary care setting, and our findings are similar to those described previously. ${ }^{30-32}$ In addition, Saelens et $\mathrm{al}^{40}$ found that adolescents randomized to a multicomponent behav- ioral weight control intervention initiated in primary care had significant decreases in BMI zscores compared with those randomized to a group offered a single session of weight counseling by a physician. A primary care-based childhood obesity program conducted at Duke University (the Duke University Healthy Lifestyles Program) ${ }^{41}$ found that enrolled patients achieved a reduction in BMI SD score and improvements in other comorbidities (blood pressure, triglycerides, total cholesterol, and insulin resistance). A recent review published in the Fournal of Obesity advocates for expanding the role of primary care in the prevention and treatment of childhood obesity $^{42}$ and recommends 9 areas in which providers can promote the prevention and treatment of childhood obesity.

One reason why there may be limited primary care-based childhood obesity interventions is because of the difficulty of implementing and sustaining a program like the FFC in primary care. We encountered several barriers related to sustained implementation of the FFC in our pilot practices, and the major themes are described in the Results.

Table 4. Lifestyle Outcomes

\begin{tabular}{lccc}
\hline HeartSmartKids Question & Baseline $(\mathrm{n}=290)$ & Change per 3 Months* & Overall $P$ Value \\
\hline Fruit and vegetable intake (servings/day) & 2.92 & +0.35 & $<.0001$ \\
Milk type: decrease fat content (high is worse) & 1.62 & -0.03 & .1925 \\
Physical activity, at least 60 minutes/day (days/week) & 3.81 & +0.45 & $<.0001$ \\
Family activity (times/week) & 2.41 & +0.21 & .0051 \\
Hours/day of screen time & 2.28 & -0.11 & .0147 \\
Sugar-sweetened beverage intake (servings/day) & 1.56 & -0.15 & $<.0001$ \\
Eating out weekly (times/week) & 1.45 & -0.11 & .0006 \\
\hline
\end{tabular}

*Averaged across all participants with any follow-up. 
Lack of time, lack of adequate staff, and lack of reimbursement were the major barriers. Lack of reimbursement was the main barrier for practices not being able to sustain FFC past the time frame of this project. Some practices were able to charge for the monthly group visits; however, the reimbursement rates did not fully cover the costs incurred by the practices. Lack of adequate staff was also identified as a barrier; some practices were able to use staff dietitians, behavioral health specialists, or health educators to deliver the FFC monthly group visits. However, many of the practices relied on medical assistants or practice managers who had little training in lifestyle modification counseling. Practices also reported screening and inviting sufficient numbers of overweight or obese children and their families to participate in the FFC, but few agreed to participate, and even fewer actually showed up for the first group visit. Practices reported that it took a significant amount of time and effort to recruit participants, and their efforts did not result in enrolling enough participants for them to feel that it was worth their time.

\section{Limitations}

There are several limitations of this pilot study, including the funders of this project requiring that all practices receive the intervention; thus randomization was not possible. However, data from a retrospective cohort study of $>25,000$ children seen in a safety net system in Colorado indicate that children in the highest risk categories for weight (85th percentile or higher) tended to maintain or increase BMI $z$-scores during this age range in usual care. ${ }^{15}$ Another limitation to this study is the inability to ascribe our FFC program changes only to our intervention, and our results for the 5-2-1-0 lifestyle changes were derived from self-reported data from the child/parent. The low completion rate also limits the ability to determine the true efficacy of the FFC. Last, this project was conducted in only 1 state, and Colorado may not be representative of other states.

\section{Conclusion}

The FFC pilot program improved clinical outcomes for childhood obesity and lifestyle risk factors, indicating a promising intervention for primary care practices. Cultural considerations and interventions that address food insecurity also need to be addressed to improve participation and retention in childhood obesity programs.

\section{References}

1. Ogden CL, Carroll MD, Kit BK, Flegal KM. Prevalence of childhood and adult obesity in the United States, 2011-2012. JAMA 2014;311:806-14.

2. National Center for Health Statistics. Health, United States. Health, United States, 2011. With special feature on socioeconomic status and health. Hyattsville (MD): US Department of Health and Human Services, Centers for Disease Control and Prevention; 2012.

3. Centers for Disease Control. Childhood obesity facts. Available from: http://www.cdc.gov/healthyyouth/ obesity/facts.htm. Accessed June 2014.

4. Daniels SR, Arnett DK, Eckel RH, et al. Overweight in children and adolescents: pathophysiology, consequences, prevention, and treatment. Circulation 2005;111:1999-2012.

5. US Department of Health and Human Services. The Surgeon General's vision for a healthy and fit nation. Rockville, MD; US Department of Health and Human Services; 2010.

6. Dietz WH. Overweight in childhood and adolescence. New Engl J Med 2004;350:855-7.

7. Freedman DS, Mei Z, Srinivasan SR, Berenson GS, Dietz WH. Cardiovascular risk factors and excess adiposity among overweight children and adolescents: the Bogalusa Heart Study. J Pediatr 2007;150: $12-7 . e 2$.

8. Li C, Ford ES, Zhao G, Mokdad AH. Prevalence of pre-diabetes and its association with clustering of cardiometabolic risk factors and hyperinsulinemia among U.S. adolescents: National Health and $\mathrm{Nu}-$ trition Examination Survey 2005-2006. Diabetes Care 2009;32:342-7.

9. Centers for Disease Control. National diabetes fact sheet: nation estimates and general information on diabetes and prediabetes in the United States, 2011. Atlanta: US Department of Health and Human Services; 2011.

10. Kushi LH, Byers T, Doyle C, et al. American Cancer Society Guidelines on nutrition and physical activity for cancer prevention: reducing the risk of cancer with healthy food choices and physical activity. CA Cancer J Clin 2006;56:254-81.

11. Khan LK, Sobush K, Keener D, et al. Recommended community strategies and measurements to prevent obesity in the United States. MMWR Recomm Rep 2009;58(RR-7):1-26.

12. Institute of Medicine. Accelerating progress in obesity prevention: solving the weight of the nation. Washington, DC: National Academies Press; 2012.

13. Barlow SE. Expert committee recommendations regarding the prevention, assessment, and treatment of 
child and adolescent overweight and obesity: summary report. Pediatrics 2007;120(Suppl 4):S164-92.

14. US Preventative Services Task Force. Obesity in children and adolescents: Screening. Release date: January 2010. Available from: www.uspreventiveservicestaskforce. org/uspstf/uspschobes.htm. Accessed September 2014.

15. McCormick EV, Dickinson LM, Haemer MA, Knierim SD, Hambidge SJ, Davidson AJ. What can providers learn from childhood body mass index trajectories: a study of a large, safety-net clinical population. Acad Pediatr 2014;14:639-45.

16. Atlantis E, Barnes EH, Singh MA. Efficacy of exercise for treating overweight in children and adolescents: a systematic review. Int J Obes (Lond) 2006; 30:1027-40.

17. Wilfley DE, Tibbs TL, Van Buren DJ, Reach KP, Walker MS, Epstein LH. Lifestyle interventions in the treatment of childhood overweight: a meta-analytic review of randomized controlled trials. Health Psychol 27;26:521-32.

18. Nemet D, Barkan S, Epstein Y, Friedland O, Kowen $\mathrm{G}$, Eliakim A. Short- and long-term beneficial effects of a combined dietary-behavioral-physical activity intervention for the treatment of childhood obesity. Pediatrics 2005;115:e443-9.

19. Whitlock EP, Williams SB, Gold R, Smith PR, Shipman SA. Screening and interventions for childhood overweight: a summary of evidence for the US Preventive Services Task Force. Pediatrics 2005;116: e125-44.

20. Herrera EA, Johnston CA, Steele RG. A comparison of cognitive and behavioral treatments for pediatric obesity. Children Health Care 2004;33:151-67.

21. Savoye M, Shaw M, Dziura J, et al. Effects of a weight management program on body composition and metabolic parameters in overweight children: a randomized controlled trial. JAMA 2007;297:2697704.

22. McCallum Z, Wake M, Gerner B, et al. Outcome data from the LEAP (Live. Eat and Play) trial: a randomized controlled trial of a primary care intervention for childhood overweight/mild obesity. Int J Obes (Lond) 2007;31:630-6.

23. Epstein LH, McCurley J, Wing RR, Valoski A. Fiveyear follow-up of family-based behavioral treatments for childhood obesity. J Consul Clin Psychol 1990; 58:661-4.

24. Epstein LH, Paluch RA, Roemmich JN, Beecher MD. Family-based obesity treatment, then and now: twenty-five years of pediatric obesity treatment. Health Psychol 2007;26:381-91.

25. Epstein LH, Valoski AM, Vara LS, et al. Effects of decreasing sedentary behavior and increasing activity on weight change in obese children. Health Psychol 1995;14:109-15.

26. Kitzmann KM, Beech BM. Family-based interventions for pediatric obesity: methodological and con- ceptual challenges from family psychology. J Fam Psychol 2006;20:175-89.

27. Nowicka P, Flodmark CE. Family in pediatric obesity management: a literature review. Int J Pediatr Obes 2008;3(Suppl 1):44-50.

28. Krebs N, Baker R, Greer F, et al. American Academy of Pediatrics Policy statement: prevention of pediatric overweight and obesity. Pediatrics 2003; 112:424-30.

29. Story MT, Neumark-Stzainer DR, Sherwood NE, et al. Management of child and adolescent obesity: attitudes, barriers, skills, and training needs among health care professionals. Pediatrics 2002; 110(1 Pt 2):210-4.

30. Endevelt R, Elkayam O, Cohen R, et al. An intensive family intervention clinic for reducing childhood obesity. J Am Board Fam Med 2014;27:321-8.

31. McGaffey AL, Abatemarco DJ, Jewell IK, Fidler SK, Hughes K. Fitwits MD: an office-based tool and games for conversations about obesity with 9- to 12-year-old children. J Am Board Fam Med 2011; 24:768-71.

32. Polacsek M, Orr J, Letourneau L, et al. Impact of a primary care intervention on physician practice and patient and family behavior: Keep ME Healthy-the Maine Youth Overweight Collaborative. Pediatrics 2009;123(Suppl 5):S258-66.

33. Duggins M, Cherven P, Carrithers J, Messamore J, Harvey A. Impact of family YMCA membership on childhood obesity: a randomized controlled effectiveness trial. J Am Board Fam Med 2010;23:323-33.

34. Hedeker D. Application of random-effects patternmixture models for missing data in longitudinal studies. Psychol Methods. 1997;2:64-78.

35. Fairclough D. Design and analysis of quality of life studies in clinical trials. New York: Chapman and Hall; 2010.

36. Papas MA, Trabulsi JC, Dahl A, Dominick G. Food insecurity increases the odds of obesity among young Hispanic children. J Immigr Minor Health 2015 Sep 16 [Epub ahead of print].

37. De Miguel-Etayo P, Muro C, Santabarbara J, et al. Behavioral predictors of attrition in adolescents participating in a multidisciplinary obesity treatment program: EVASYON study. Int J Obes (Lond) 2016; 40:84-7.

38. Zeller M, Kirk S, Claytor R, et al. Predictors of attrition from a pediatric weight management program. J Pediatr 2004;144:466-70.

39. Gill RS, Karmali S, Hadi G, Al-Adra DP, Shi X, Birch DW. Predictors of attrition in a multidisciplinary adult weight management clinic. Can J Surg 2012;55:239-43.

40. Saelens BE, Sallis JF, Wilfley DE, Patrick K, Cella JA, Buchta R. Behavioral weight control for 
overweight adolescents initiated in primary care. Obes Res 2002;10:22-32.

41. Dolinsky DH, Armstrong SC, Walter EB, Kemper AR. The effectiveness of a primary care-based pediatric obesity program. Clin Pediatr 2012;51:345-53.
42. Vine M, Hargreaves MB, Briefel RR, Orfield C. Expanding the role of primary care in the prevention and treatment of childhood obesity: a review of clinic- and community-based recommendations and interventions. J Obes 2013;2013:172035. 